\title{
Flow-Injection Spectrophotometric Determination of Sulfadiazine and Sulfamethoxazole in Pharmaceuticals and Urine
}

\author{
Jing Fan, ${ }^{\dagger}$ Yahong Chen, Suling Feng, Cunling Ye, and Jianji Wang \\ School of Chemical \& Environmental Sciences, Henan Normal University, \\ Key Laboratory of Environmental Science and Engineering of Henan Education Commission, \\ Xinxiang, Henan 453002, People's Republic of China
}

\begin{abstract}
A rapid and sensitive flow-injection spectrophotometric method is proposed for the determination of sulfadiazine and sulfamethoxazole. This method is based on the diazotization of sulfonamide with sodium nitrite, and a coupling reaction of the diazo-compound with $\alpha$-naphthylamine. The optimum experimental conditions are obtained by using the controlled and weighted centroid simplex method. The linear ranges for the determination of sulfadiazine and sulfamethoxazole are $0.2-20 \mu \mathrm{g} \mathrm{ml}^{-1}$ and $0.1-20 \mu \mathrm{g} \mathrm{ml}^{-1}$, and their detection limits are $0.06 \mu \mathrm{g} \mathrm{ml}^{-1}$ and $0.05 \mu \mathrm{g} \mathrm{ml}{ }^{-1}$, respectively, and the sampling frequency is 130 samples per hour. The method has been used to determine sulfadiazine and sulfamethoxazole in pharmaceuticals and urine without separation. The results are in agreement with those obtained by a high-performance liquid chromatograph technique at the $95 \%$ confidence level.
\end{abstract}

(Received May 7, 2002; Accepted October 21, 2002)

\section{Introduction}

Sulfadiazine and sulfamethoxazole are sulfonamides used in the treatment of urinary-tract infectious, pneumocystis pneumonia, chronic bronchitis, meningococcal meningitis, acute otitis media, and toxoplasmosis. ${ }^{1}$ They are now available as widely used pharmaceutical products and veterinary practices. At present, the standard methods for the determination of sulfadiazine and sulfamethoxazole are the titrimetric method ${ }^{2,3}$ and the high-performance liquid chromatographic (HPLC) technique. ${ }^{4-6}$ The former is simple in operation and the titration error is small. However, the sensitivity is not suitable for low concentrations. The later is sensitive, but uses an elevated volume of pure organic reagents and an expensive apparatus.

Previously, aromatic amines were determined by a diazotization reaction. ${ }^{7}$ It is based on the conversion of free primary aryl amine into a diazonium salt by a reaction with nitrous acid; the salt then rapidly forms an azo-dye with a chromogenic reagent, such as $N$-(1-napthyl)ethylenediamine (NED). The procedure requires the removal of excess nitrous acid by sulfamic acid, the stabilization of intermediary diazonium salt at low temperature and the expulsion of nitrogen bubbles.

By applying FIA techniques, the destruction of excess nitrite can be avoided by using a low nitrite concentration, and the side-reactions can be minimized by shortening the reaction time. Therefore, the sensitivity is increased for absorptiometric measurements. Fogg et al. ${ }^{8}$ reported an FIA procedure for the determination of aromatic amines by monitoring at a glassy carbon electrode. The linear range of the determination was 5 $40 \mu \mathrm{g} \mathrm{ml}{ }^{-1}$. The sampling frequency was not reported.

$\dagger$ To whom correspondence should be addressed.

E-mail: JWang@henannu.edu.cn
Koupparis ${ }^{9}$ described an FIA procedure for the determination of sulfonamides based on diazotization and coupling with NED by spectrophotometric monitoring of the dye. The linear range of

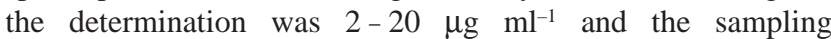
frequency was $72 \mathrm{~h}^{-1}$. Diazotization and coupling in a micellar medium were applied to the determination of arylamines and sulfonamides with a simple FIA procedure. ${ }^{10}$ The limit of detection was in the range $0.2-0.5 \mu \mathrm{g} \mathrm{ml}^{-1}$, and no sampling frequency was reported. Recently, Mellado et al. ${ }^{11}$ proposed a method for the determination of sulfadiazine, which is based on the solid-phase reduction of nitrate using copperized cadmium. The linear range and sampling frequency were $0.5-50 \mu \mathrm{g} \mathrm{ml}^{-1}$ and $72 \mathrm{~h}^{-1}$, respectively.

In this work, a more sensitive and selective flow-injection spectrophotometric method was developed for the determination of sulfadiazine and sulfamethoxazole in pharmaceuticals and urine without any separation. The procedure is based on the diazotization reaction of sulfonamide with sodium nitrite in an acidic medium; the formed diazonium salt is then coupled with $\alpha$-naphthylamine. This method does not need to get rid of excess sodium nitrite because of the low concentration of $\mathrm{NaNO}_{2}$ used. The sampling frequency reaches $130 \mathrm{~h}^{-1}$. The results compared well with those obtained by the highperformance liquid chromatographic method.

\section{Experimental}

\section{Apparatus}

The flow-injection system used in this work is shown in Fig. 1. The manifold consisted of $0.7 \mathrm{~mm}$ i.d. polytetrafluoroethylene (PTFE) tubing. The flow-injection analysis system also included the following equipments. A sixchannel peristaltic pump (Shanghai Instrument Plant) fitted with Tygon pump tubing was used for the propulsion of fluids; 


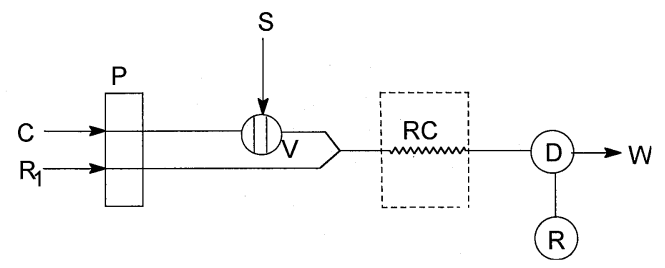

Fig. 1 Schematic diagram of the flow system. C, water carrier; D, spectrophotometric cell; $\mathrm{P}$, peristaltic pump; $\mathrm{R}$, recorder; $\mathrm{R}_{1}, \alpha$ naphthylamine solution; S, sample or reference solution (hydrochloric acid + sodium nitrite + sulfonamides + sodium acetate); $\mathrm{V}$, injection valve; $\mathrm{W}$, waste; $\mathrm{RC}$, reaction coil.

sample solutions were introduced into the flow-line by a valve fitted with a by-pass coil; a Model 722 spectrophotometer (Shanghai No. 3 Analytical Instrument Plant) with a $10-\mathrm{mm}$ flow-through cell was used as the detector; the signal output of the detector was recorded with an XWT-204 recorder, with the recorder response being $40 \mathrm{mV} / \mathrm{cm}$ (Shanghai Dahua Instrument Plant); the reaction coil was immersed in a Model 501 circulating thermostated bath (Chongqing Instrument Plant). For a comparison, HP1100 high-performance liquid chromatography was also used for the determinations. The procedure described in United States Pharmacopoeia $23^{4}$ was followed closely.

\section{Reagents}

Sulfadiazine and sulfamethoxazole (China Pharmaceuticals \& Biological Inspection Institute, Beijing) stock solutions (1.0 mg $\mathrm{ml}^{-1}$ ) were prepared by dissolving $0.1000 \mathrm{~g}$ of sulfadiazine or sulfamethoxazole in $100 \mathrm{ml}$ of water. Working solutions were prepared by suitable dilution. A sodium nitrite (Merck) stock solution $\left(1.0 \mathrm{mg} \mathrm{ml}^{-1}\right)$ and the working solution were obtained in the same way. An $\alpha$-naphthylamine (Beijing Chemical Reagent Ltd.) solution $\left(1.5 \mathrm{mg} \mathrm{ml} \mathrm{ml}^{-1}\right)$ was freshly prepared before a measurement by dissolving $0.0750 \mathrm{~g}$ of $\alpha$ naphthylamine in $50 \mathrm{ml}$ of water. A sodium acetate (Beijing Chemical Plant) solution $(0.2 \mathrm{M})$ was prepared as usual.

All reagents were of analytical or guaranteed grade, and were prepared using distilled-deionized water.

\section{Manifold and procedure}

As shown in Fig. 1, the carrier solution (water) and the $\alpha$ naphthylamine solution were each pumped into analytical lines at the same flow rate. The sample solution was mixed with sodium nitrite, hydrochloric acid and sodium acetate solutions, and about $5 \mathrm{~min}$ was allowed for the diazotization reaction. The mixture was introduced into the carrier stream by a loop-valve injector when the baseline was stable, and then merged with $\alpha$ naphthylamine solutions. The coupling reaction took place in a reaction coil immersed in a thermostated bath. The absorbances (A) at $538 \mathrm{~nm}$ for sulfadiazine and $528 \mathrm{~nm}$ for sulfamethoxazole were monitored and the peak heights measured, respectively. The optimum conditions listed in Table 1 for the determination were applied in the experimental procedure. At least three injections were made for every sample solution. Although a blank without sulfonamides was treated in the same way as the samples, no absorbance was observed. The concentration of the analyte can be established using the calibration curves of $A$ versus the concentration of sulfadiazine or sulfamethoxazole obtained from reference solutions under the same working conditions.
Table 1 Optimum conditions for the determination of sulfadiazine and sulfamethoxazole obtained by the controlled and weighted centroid simplex method

\begin{tabular}{lcc}
\hline \multirow{2}{*}{ Operating parameter } & \multicolumn{2}{c}{ Simplex optimum } \\
\cline { 2 - 3 } & Sulfadiazine & Sulfamethoxazole \\
\hline $\mathrm{HCl}(\mathrm{M})$ & $5.6 \times 10^{-3}$ & $1.2 \times 10^{-2}$ \\
$\mathrm{NaNO}_{2}(\mathrm{M})$ & $8.4 \times 10^{-5}$ & $8.4 \times 10^{-5}$ \\
$\mathrm{NaAc}(\mathrm{M})$ & $1.6 \times 10^{-3}$ & $8.8 \times 10^{-3}$ \\
$\alpha$-Naphthylamine $(\mathrm{M})$ & $1.6 \times 10^{-3}$ & $1.7 \times 10^{-3}$ \\
Coil length $(\mathrm{cm})$ & 125.0 & 100.0 \\
Sample volume $(\mu \mathrm{l})$ & 239.0 & 239.3 \\
Flow rate $\left.(\mathrm{ml} \mathrm{min})^{-1}\right)$ & 1.41 & 1.45 \\
Temperature $\left({ }^{\circ} \mathrm{C}\right)$ & 35.0 & 30.0 \\
\hline
\end{tabular}

\section{Treatment of samples}

Several tablets containing sulfadiazine or sulfamethoxazole were accurately weighed, ground and powdered. An amount of this powder equivalent to about $2.0 \mathrm{~g}$ of sulfadiazine or sulfamethoxazole was dissolved in a sodium hydroxide solution $(0.1 \mathrm{M})$ and hydrochloric acid solution $(0.5 \mathrm{M})$, respectively. They were transferred into $250 \mathrm{ml}$ volumetric flasks, and diluted to the mark with water. The contents of the flasks were shaken. They were then filtered and the first portion of the filtrate rejected. The amount of the remaining filtrate was further diluted with water to adjust the concentration to meet the requirement of the adopted experimental conditions.

Urine samples were collected 4-6 h after the patients took sulfamethoxazole tablets. These samples were filtered and further diluted with water to adjust the concentration to meet the requirement of the adopted experimental conditions.

\section{Results and Discussion}

Optimization of variables

Choice of the medium. In the proposed procedure, sulfuric acid, hydrochloric acid, phosphoric acid, and acetic acid solutions were tried as the reaction medium. Under the same condition, it was found that the signal of absorbance was higher in a hydrochloric acid solution. Therefore, hydrochloric acid was selected as the best reaction medium.

Influence of the diazotization reaction time. Different diazotization reaction times were tried in the proposed experiments. It was shown that the absorbance was maximum and stable within 5-10 min. Thus, 5 min was adopted as the diazotization reaction time.

Simplex optimization of variables. Firstly, a univariate method was conducted over a wide range of values for each factor. The reagent concentrations, length of the reaction coil, sample volume and temperature were identified as the most important parameters for optimization. Secondly, the controlled and weighted centroid simplex method ${ }^{12}$ was used to achieve the maximum absorbance. The simplex was halted after 25 and 22 vertexes, respectively, for the determination of sulfadiazine and sulfamethoxazole. The progress of the simplex is shown in Figs. 2 and 3, indicating a gradual improvement in the peak height. The centroid (mean of eight retention points) was taken as the optimum operating conditions. Table 1 lists the optimum values obtained for each of the eight factors investigated. 
Table 2 Influence of possible interfering species

\begin{tabular}{lcc}
\hline \multicolumn{1}{c}{ Foreign species } & $\begin{array}{c}\text { [Foreign species]/ } \\
\text { [sulfadiazine] }\end{array}$ & $\begin{array}{c}\text { [Foreign species]/ } \\
\text { [sulfamethoxazole] }\end{array}$ \\
\hline $\mathrm{Cl}^{-}, \mathrm{SO}_{4}{ }^{2-}, \mathrm{NO}_{3}{ }^{-}$ & 3000 & 3000 \\
$\mathrm{~K}^{+}, \mathrm{Na}^{+}, \mathrm{Starch}^{2}, \mathrm{Urea}$ & 1500 & 1500 \\
$\mathrm{Ca}^{2+}, \mathrm{Ba}^{2+}, \mathrm{Zn}^{2+}, \mathrm{NH}_{4}{ }^{+}$, & 1000 & 1000 \\
$\mathrm{Uric}^{2}$ acid, Sodium & 1000 & 1000 \\
Bitartrate, Glucose, & 1000 & 1000 \\
Fructose & & \\
Vitamin $\mathrm{B}_{1}$ & 500 & 500 \\
$\mathrm{Vitamin}_{6}$, Lactic acid & 750 & 750 \\
$\mathrm{Cu}^{2+}$ & 500 & 50 \\
$\mathrm{Fe}^{3+}$ & 200 & 200 \\
Sodium citrate & 75 & 120 \\
Sodium malonate & 50 & 100 \\
\hline
\end{tabular}

\section{Characteristics of the method}

A series of reference solutions were injected into the manifold under the optimized conditions to test the linearity of the calibration graph. The linear relationship between $A$ and the concentration of sulfadiazine or sulfamethoxazole was obtained over the range of $0.2-20 \mu \mathrm{g} \mathrm{ml}^{-1}$ and $0.1-20 \mu \mathrm{g} \mathrm{ml} \mathrm{m}^{-1}$, respectively. The detection limit (taken as three-times the standard deviation of the reagent blank/slope) was $0.06 \mu \mathrm{g} \mathrm{ml}^{-1}$ and $0.05 \mu \mathrm{g} \mathrm{ml}^{-1}$, respectively. The calibration equations obtained by the least-squares method were given by

$$
\begin{array}{ll}
A_{1}=-0.00584+0.04744 C_{1} & (\gamma=0.9983, n=7), \\
A_{2}=0.01241+0.05537 C_{2} & (\gamma=0.9979, n=7),
\end{array}
$$

where $C_{1}$ and $C_{2}$ are the concentrations of sulfadiazine and sulfamethoxazole in $\mu \mathrm{g} \mathrm{ml}^{-1}$, and $\gamma$ is the linear correlation coefficient. Both analytes could be determined at a sampling frequency of $130 \mathrm{~h}^{-1}$.

\section{Interference of foreign species}

The effects of interfering species in pharmaceuticals and urine were investigated concerning the determination of $4.0 \mu \mathrm{g} \mathrm{ml}^{-1}$ sulfadiazine and sulfamethoxazole. The possible interfering species examined are listed in Table 2. When the permitted relative deviation from absorbance is larger than $\pm 5 \%$, the examined species may cause a significant alteration of the results. It can be seen that the proposed method has good selectivity.

\section{Applications to real samples}

The proposed method was applied to the determination of sulfadiazine and sulfamethoxazole in pharmaceuticals and urine by using the procedure described in the experimental section. Figure 4 shows the response of the blank and a sample analysis by FIA. In order to examine these results, the HPLC technique was also used for determinations by closely following a procedure described in the literature. ${ }^{4}$ The results obtained by the two different methods are statistically compared in Table 3. It can be seen that no significant differences were found between them. This confirms the validity of the method proposed in this work.

\section{Conclusions}

A new flow-injection spectrophotometric method was proposed

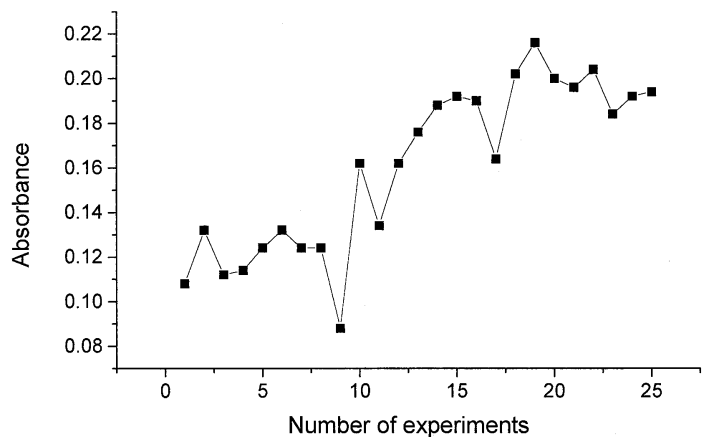

Fig. 2 Response function progress of the simplex for the determination of sulfadiazine.

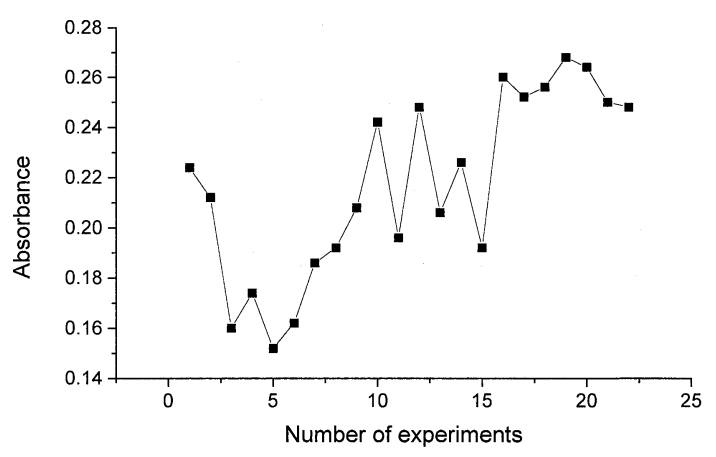

Fig. 3 Response function progress of the simplex for the determination of sulfamethoxazole.
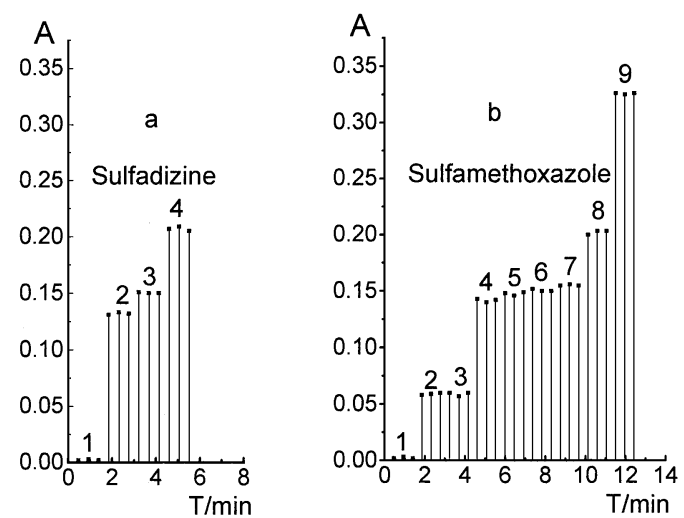

Fig. 4 Response of the blank and samples analysis by the FIA. a: 1, blank; 2, sulfadizine tablet $1(2.91 \mu \mathrm{g} / \mathrm{mL}) ; 3$, sulfadizine tablet 2 $(3.28 \mu \mathrm{g} / \mathrm{mL}) ; 4$, veterinary powder $(4.49 \mu \mathrm{g} / \mathrm{mL})$. b: 1 , blank; 2 , urine $2(0.84 \mu \mathrm{g} / \mathrm{mL}) ; 3$, urine $1(0.84 \mu \mathrm{g} / \mathrm{mL}) ; 4$, Xie Li ting tablet 1 (2.34 $\mu \mathrm{g} / \mathrm{mL}) ; 5$, Xie Li Ting Tablet $2(2.49 \mu \mathrm{g} / \mathrm{mL}) ; 6$, sulfamethoxazole tablet $2(2.50 \mu \mathrm{g} / \mathrm{mL}) ; 7$, sulfamethoxazole tablet 1 $(2.58 \mu \mathrm{g} / \mathrm{mL}) ; 8$, urine $3(3.42 \mu \mathrm{g} / \mathrm{mL}) ; 9$, urine $4(5.66 \mu \mathrm{g} / \mathrm{mL})$

for the determination of sulfadiazine and sulfamethoxazole. It has been shown that the proposed method is rapid, simple, and sensitive for the determination of sulfadiazine and sulfamethoxazole in pharmaceuticals and urine. It provides accurate and precise results over a wider range of concentrations with a higher sampling frequency and good selectivity. These facts encourage the application of this method for on-line automatic analysis. 
Table 3 Comparison of the concentration of sulfonamides determined by the proposed FIA and by HPLC

\begin{tabular}{|c|c|c|c|c|}
\hline Sulfonamide & Sample & Proposed method ${ }^{\mathrm{a}}$ & HPLC & $t^{\mathrm{b}}$ \\
\hline \multirow[t]{3}{*}{ Sulfadiazine } & Sulfadiazine Tablet 1 (g/tablet) & $0.507 \pm 0.002$ & $0.505 \pm 0.006$ & 2.72 \\
\hline & Sulfadiazine Tablet 2 (g/tablet) & $0.509 \pm 0.001$ & $0.505 \pm 0.001$ & 2.41 \\
\hline & Veterinary Powder (\%) & $95.3 \pm 2.0$ & $96.3 \pm 0.8$ & 1.41 \\
\hline \multirow[t]{8}{*}{ Sulfamethoxazole } & Sulfamethoxazole Tablet 1 (g/tablet) & $0.396 \pm 0.004$ & $0.393 \pm 0.011$ & 1.53 \\
\hline & Sulfamethoxazole Tablet 2 (g/tablet) & $0.403 \pm 0.004$ & $0.402 \pm 0.006$ & 0.99 \\
\hline & Xie Li Ting Tablet 1 (g/tablet) & $0.388 \pm 0.005$ & $0.385 \pm 0.016$ & 2.05 \\
\hline & Xie Li Ting Tablet 2 (g/tablet) & $0.407 \pm 0.004$ & $0.405 \pm 0.010$ & 1.09 \\
\hline & Urine $1\left(\mathrm{mg} \mathrm{ml}^{-1}\right)$ & $0.071 \pm 0.002$ & $0.070 \pm 0.014$ & 1.81 \\
\hline & Urine $2\left(\mathrm{mg} \mathrm{ml}^{-1}\right)$ & $0.071 \pm 0.002$ & $0.070 \pm 0.001$ & 1.39 \\
\hline & Urine $3\left(\mathrm{mg} \mathrm{ml}^{-1}\right)$ & $0.198 \pm 0.002$ & $0.197 \pm 0.002$ & 2.46 \\
\hline & Urine $4\left(\mathrm{mg} \mathrm{ml}^{-1}\right)$ & $0.308 \pm 0.001$ & $0.307 \pm 0.002$ & 1.56 \\
\hline
\end{tabular}

a. Mean \pm standard deviation of five determinations. b. Theoretical value $=2.78, n=5$ with $95 \%$ confidence limits.

\section{Acknowledgements}

Financial support from the Science Foundation of Henan Education Commission is gratefully acknowledged.

\section{References}

1. Sulfonamides in "American Hospital Formulary Service: Drug Information", ed. G. K. McEvoy, 1993, American Hospital Formulary Service, Inc., Bethesda, 472.

2. United States Pharmacopoeia, XXIth Revision, National Formulary XVIth ed., 1985, U. S. Pharmacopeial Convention, Rockville.

3. European Pharmacopoeia, Consejo de Europa (III-1975), 1981, Consejo General de Colegios Oficiales de Farmaceuticos, Spain.
4. United States Pharmacopeia National Formulary, USP 23, NF 18, 1995, II, 1464.

5. De. Baeres, K. Baert, S. Croubels, J. Busser, K. De Wasch, and P. De Bachcr, Analyst [London], 2000, 125, 409.

6. A. Kebriacezadeh, A. Zarghi, R. Ahonadkhaniha, A. Khoddam, and A. J. Ebrahimian, Pharm. Pharmacol. Commun., 2000, 6, 113.

7. S. S. Tseng and T. J. Smith, Anal. Lett., 1994, 27, 1507.

8. A. G. Fogg, N. K. Bsebsu, and M. A. Abdalla, Analyst, 1982, 107, 1462.

9. M. A. Koupparis and P. I. Anagnostopoulou, Anal. Chim. Acta, 1988, 204, 271.

10. J. S. Esteve Romero and G. Ramis Ramos, Anal. Chim. Acta, 1991, 242, 143.

11. A. Mellado Romero, C. Gomez Benito, and J. Martinez Calatayud, Anal. Chim. Acta, 1995, 308, 451.

12. J. Fan, C. Ye, S. Feng, G. Zhang, and J. Wang, Talanta, 1999, 50, 893. 